Revista de la red interuniversitaria de estudios sobre las

literaturas rioplatenses contemporáneas en Francia

$12 \mid 2015$

Prodigios borgeanos: ficciones, historias, teologías

\title{
De Almotásim a Abenjacán : dinámicas entre composición y lectura en la ficción de Borges
}

\author{
Pablo Martín Ruiz
}

\section{OpenEdition}

\section{Journals}

Edición electrónica

URL: http://journals.openedition.org/lirico/1961

DOI: $10.4000 /$ lirico.1961

ISSN: 2262-8339

Editor

Réseau interuniversitaire d'étude des littératures contemporaines du Río de la Plata

Referencia electrónica

Pablo Martín Ruiz, «

De Almotásim a Abenjacán : dinámicas entre composición y lectura en la ficción de Borges »

Cuadernos LIRICO [En línea], 12 | 2015, Puesto en línea el 23 enero 2015, consultado el 20 abril 2019

URL : http://journals.openedition.org/lirico/1961 ; DOI : 10.4000/lirico.1961

Este documento fue generado automáticamente el 20 abril 2019.

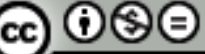

Cuadernos LIRICO está distribuido bajo una Licencia Creative Commons Atribución-NoComercial-

SinDerivar 4.0 Internacional. 


\section{De Almotásim a Abenjacán : dinámicas entre composición y lectura en la ficción de Borges}

\section{Pablo Martín Ruiz}

Decir que unas pocas páginas casi escondidas al final de un libro de ensayos constituyen el inicio de una de las mayores transformaciones de la historia de la ficción parece un error o una broma. Y sin embargo ese es el destino que podemos atribuirle a la silenciosa publicación en 1936, en la sección final de

Historia de la eternidad

, de «El acercamiento a Almotásim », el núcleo temprano de lo que sería la reinvención borgeana de la ficción. Hasta ese momento, Borges era reconocido como autor de poesía y de ensayos. El Borges cuentista se limitaba al relato malevo « Hombre de la esquina rosada », que había publicado en 1933 después de un par de versiones previas y reversiones publicadas con distintos títulos desde 1927, y a las reescrituras más o menos

paródicas de

Historia universal de la infamia

, publicado en 1935. Recién en 1939 publicaría « Pierre Menard, autor delQuijote

", para cerrar una década de producción narrativa relativamente escasa. Poco hacía prever que a partir de 1941, con la publicación de

El jardín de senderos que se bifurcan

, Borges daría a conocer uno de los conjuntos de cuentos más influyentes del siglo, que

llegaría a su culminación más de una década después con la publicación de los últimos cuentos agregados a las segundas ediciones de

El Alephen 1952 y deFiccionesen 1956. 
La relativa lentitud de la consolidación del Borges narrador tal vez refleje el ritmo de la paulatina y reflexionada elaboración, a lo largo de los años treinta, de una muy particular poética de la ficción. A la ya vasta colección de interpretaciones y glosas que esos cuentos y esa poética han generado quisiera agregar un comentario sobre ciertos elementos que recorren esa producción narrativa, relacionados con ideas acerca de la composición literaria y figuras de autor asociadas, con el uso de modelos de lectura como matrices de escritura, y sobre todo con ciertos modos particulares en que composición y lectura moldearon la ficción de Borges y dieron forma a la poética que la acompaña. La tesis que voy a tratar de justificar es que buena parte de la ficción de Borges puede pensarse como resultado de fusionar o combinar dos modelos de lectura específicos, que a su vez Borges asocia con ciertas figuras de autor derivadas de modos de concebir la composición y ubicadas en tensión con las vanguardias.

\section{Relato de composición y figuras de poeta}

En 1960 Borges publica un libro misceláneo al que titulaEl hacedor

, palabra que dijo haber tomado del inglésmaker. En la tradición inglesa, la palabramaker

se había usado para referirse a los poetas renacentistas de la corte. La misma palabra tiene también una tradición de uso en francés bajo la forma

facteur, nombre que se daban a sí mismos por ejemplo losgrands rhétoriqueurs

en la misma época. No es casual que estas palabras equivalentes hayan circulado en las

dos lenguas impulsadas por aires renacentistas, ya que desde luego se trata de una traducción etimológica de la palabra " poeta », cuya raíz griega significa « el que hace ». La referencia griega no es ociosa, teniendo en cuenta que este libro de Borges abre con un texto breve en prosa llamado precisamente «El hacedor ", que es una especulación sobre

Homero, y se cierra con el poema "Arte poética ", en el que no solo se retoma una

tradición clásica sino que los dos nombres que aparecen en el poema son los de los griegos Ulises y Heráclito. Este « hacedor » convocado por el título de Borges implica una imagen o figura de autor con determinadas características y cuya génesis se remonta a los debates sobre poética de la antigua Grecia, una figura que desde temprano en su carrera Borges adoptó y consolidó y de la que en ocasiones también, aunque más retóricamente que de hecho, se distanció.

La idea activa de « hacer » en el sentido de crear poesía se opone históricamente a la idea pasiva de inspiración. Mientras la inspiración supone el abandono de las facultades mentales conscientes para componer un texto sobre el que se tiene poco control, el « hacedor », al menos en principio, recurre a la inteligencia y la razón para componer a partir de un plan previo y mediante una cadena de decisiones deducidas o razonadas de

las que deriva el texto. Es decir que se trata de una figura de autor que es, vista con detenimiento, una consecuencia de una teoría de la composición, o mejor dicho, de un relato de composición. Me detengo un momento en este concepto porque es el concepto alrededor del que voy a organizar lo que sigue. 
El relato de composición no es más que la narración de la concepción y el proceso de escritura de la obra literaria. El ejemplo canónico sería el ensayo de Poe « Filosofía de la composición », en el que Poe expone detalladamente el supuesto proceso de escritura de

su poema « El cuervo ». Pero el relato de composición suele actuar de modos menos ostensibles y declarados, y si bien textos como el de Poe son relativamente recientes, el relato de composición ha estado presente, cumpliendo una serie de funciones, desde el comienzo de la crítica literaria. No necesita provenir del autor para funcionar y producir efectos. Tomemos el ejemplo de

Platón. Cuando Platón les niega a los poetas un lugar digno en las jerarquías de su sociedad ideal, ese juicio se basa en el modo en que Platón concebía o imaginaba el acto de composición literaria, en aquello que él suponía que el poeta hace en el momento de producir sus textos. Platón presenta básicamente dos argumentos contra los poetas. En el Ion

, y de modo repetido en otros diálogos, tenemos la imagen del poeta enajenado de su razón, alguien que cuando compone no es más que un imán en una cadena de imanes. El segundo argumento es el mimético y aparece en la República

. En este caso, el poeta es como un espejo que simplemente refleja la realidad que lo rodea. $\mathrm{O}$ sea que Platón imagina al poeta ya sea como inspirado y fuera de sí o como meramente mimético y mecánico, y además recurre a dos objetos inanimados como análogos de lo que el poeta hace en el acto de componer. En ambos casos se trata de alguien que abandona sus facultades conscientes y prescinde de la razón, y por lo tanto el poeta es sentenciado. Es decir que Platón, que de algún modo sienta las bases de lo que será la crítica literaria en Occidente, coloca a la composición en el centro del discurso sobre la literatura.

La figura que será la contrapartida de la imaginada por Platón, la del poeta consciente y Poética que razona, es el protagonista implícito de la

de Aristóteles. Al afirmar que el poeta necesita estar en posesión de cierto saber y tomar decisiones basadas en ese saber para componer sus obras, Aristóteles postula a la razón como condición del buen poeta y por lo tanto como personaje prominente del relato de composición. Las formas que estos dos polos de la figura del autor han adoptado a lo largo de los siglos son múltiples y cambiantes, pero la oposición se ha mantenido con una persistencia llamativa. Al punto que la figura del poeta razonador, propia de lo que podemos llamar la tradición aristotélica de composición, alcanza la que tal vez sea su máxima cristalización más de dos mil años después, a mediados del siglo diecinueve, con

«Filosofía de la composición » la publicación de 
. Recordemos que en este ensayo Poe presenta el proceso de escritura en términos de deducción lógica y en contra del modelo romántico/platónico del poeta inspirado. De hecho, Poe escribe este ensayo como parte del debate con sus adversarios, los poetas trascendentalistas representados por Emerson. El ensayo de Poe es una novedad casi absoluta, pero también podemos decir que estaba latente desde hacía siglos en las obras cuidadosamente premeditadas y formalmente trabajadas de los trágicos griegos, de los

trovadores y de Dante ; en los sonetos del Renacimiento italiano, o en los tratados neoclásicos de Boileau y de Pope, todos ellos representantes de lo que podemos identificar como una larga tradición aristotélica de creadores conscientes, de artífices o hacedores 1 .

Este texto de Poe tuvo además efectos concretos y de amplio alcance que conviene repasar, porque esos efectos tocan directamente a Borges y en particular al Borges que empezaba a imaginarse escritor en la adolescencia ginebrina. Uno de esos efectos fue que la figura del poeta razonador que el ensayo promueve, un poeta que produce textos de modo que, en palabras de Poe, « ningún aspecto de su composición se debe a accidente o a intuición »(Poe 2014 [web])2 , cruzará el Atlántico y se hará prominente en Francia, encarnada por Mallarmé y por Paul Valéry, que leyeron el ensayo de Poe en sus años de formación y permanecieron fieles a sus ideas y a su modelo de poeta con devoción manifiesta. Recordemos que Mallarmé narró la composición de uno de sus poemas tempranos a la manera de Poe y que su obra mayor,

UnCoup de dés

, plantea desde la primera línea el combate al azar promovido por Poe. En el caso de Valéry, el primer ensayo que escribió fue un juvenil análisis y elogio de «Filosofía de la composición »

, y al final de su vida dictó seminarios de poética en los que el método compositivo de Poe estaba en primer plano. La vigencia de esta figura de autor se mantuvo hasta que el modelo romántico reapareció nuevamente a comienzos del siglo XX, proclamado en los manifiestos de la vanguardia y particularmente en los del Surrealismo. En explícito rechazo del modelo de poeta lúcido que encarnaba Valéry, a quien atacaron y parodiaron en sus textos, Breton y los surrealistas promoverán la escritura automática como procedimiento privilegiado de composición. La adopción por parte del Surrealismo de procedimientos específicos de composición no es de ninguna manera excepcional entre los movimientos y artistas de vanguardia, sino que es más bien la norma. Enumeremos algunos de esos procedimientos : collages, cadáver exquisito, operaciones del azar, serialismo dodecafónico en música,

action paintingen pintura, losready-mades

de Duchamp, las asociaciones fonéticas de Raymond Rousell, elfrottage

, o incluso los métodos desarrollados por los cubistas o constructivistas son justamente eso : procedimientos de composición, la forma de posibles relatos de composición. Es decir que la composición y las maneras de imaginarla y construirla han estado en el centro de múltiples debates y proyectos creativos. Muchas de las posiciones que pueden detectarse en el campo literario surgen de suponer o promover un modo en que las obras se originan y se escriben, a partir del cual se construye un relato, explícito o implícito, real o imaginario, sobre ese proceso. 


\section{Borges entre vanguardistas}

Uno de los primeros textos en los que aparece la firma de Borges es del año 1920 y tiene

«Carta colectiva con un texto de escritura automática »

, que él y los demás miembros del grupo ultraísta enviaron a Tristan Tzara, fundador del dadaísmo, y en la que expresaban

«nuestra adhesión dichosa a Dada »(Textos recobrados 1919-1929

: 44-47). El debate entre escritura automática y su opuesto, la escritura planificada encarnada en ese momento en Francia por Valéry, puede verse como una recreación contemporánea del viejo debate entre inspiración y razón que tiene sus raíces en la Grecia antigua. Borges, en contra de lo que él mismo y sus colegas del Ultraísmo habían proclamado en esa carta colectiva, tomará partido desde temprano por el bando de la razón y pasará el resto de su vida de escritor desarrollando una poética en las antípodas

de la escritura automática surrealista. A mediados de la década del treinta, Borges ya estaba claramente alineado. Su amigo Adolfo Bioy Casares, recordando una conversación que habían tenido en 1935 o 1936, escribió :

Yo estaba seguro de que para la creación artística y literaria era indispensable la libertad total que reclamaba uno de mis autores, y andaba como arrebatado por un manifiesto leído no sé dónde, que únicamente consistía en la repetición de dos palabras : Lo nuevo. De modo que me puse a ponderar la contribución a las artes y a las letras del sueño, de la irreflexión, de la locura. Me esperaba una sorpresa. Borges abogaba por el arte deliberado, tomaba partido con Horacio y con los profesores, contra mis héroes, los deslumbrantes poetas y pintores de vanguardia.

(Bioy Casares $2006: 28-9$ )

Agrego dos observaciones. A partir de los años sesenta, Borges se esforzaría por atenuar su imagen de artista ultraconsciente y razonador, como puede verse en los prólogos de sus últimos libros de poesía, en los que enfatiza el aspecto onírico y mágico del hecho poético. Por otra parte, Borges siempre mantuvo una distancia irónica con respecto a ciertas figuras de artista consciente, especialmente si estaban asociadas con Francia. En

Antes de redactar una línea, el escritor francés quiere comprenderse, definirse, clasificarse. El inglés escribe con inocencia, el francés lo hace a favor de $a$, contrab, en función dec, haciad

. Se pregunta (digamos) : ¿Qué tipo de sonetos debe emitir un joven ateo, de tradición católica, nacido y criado en el Nivernais pero de ascendencia bretona, afiliado al partido comunista desde 1944 ?

(Textos recobrados1931-1955: 247) $)^{3}$.

Pero a pesar de estas precauciones no cabe mayor duda de que Borges afirma una figura de autor identificada con la aplicación de la razón y que entiende la creación literaria como una actividad intelectual deliberada. Esa figura de autor, por otra parte, va a ser

una de las herramientas preferidas de Borges en su estratégico combate con las vanguardias, aunque también va a ser, de un modo algo más subterráneo, una línea de 
Esta oposición no debería reducirse a un simple esquema rudimentario basado en los trazos gruesos de una generalización acerca de la creación literaria, sino que se trata de un par de opuestos que funciona dentro de un sistema de múltiples pares de opuestos que

Borges pone a funcionar en su literatura. Otros de esos pares son clásico y romántico, platónico y aristotélico, local y universal, literatura inglesa y literatura francesa, novela psicológica y novela de aventuras, cine de autor y cine de Hollywood, caos y orden, originalidad y reescritura, Borges y Borges. Se trata de dicotomías a partir de las cuales construye sus posiciones en el campo literario y que le permiten la afirmación o inversión de valores, la reformulación de debates, la identificación entusiasta o la reprobación caprichosa de autores y de obras

.Y también abren el camino a la paradoja : no hay paradoja sin un par de opuestos que aspiran a la identidad.

En particular, la oposición entre vanguardia y arte deliberado, entre poetas irreflexivos y Horacio, estructura una serie de textos centrales de la construcción y exposición de la poética de Borges. Uno de esos textos es el prólogo que Borges escribe en 1940 a La invención de Morel de Bioy Casares. Podemos detenernos en una frase de ese prólogo, en la que Borges elogia lo que llama novela de aventuras :

La novela de aventuras no se propone como una transcripción de la realidad: es un objeto artificial que no sufre ninguna parte injustificada "(OCIV :

28). En este juicio de valor hay dos criterios actuando. Por un lado, un criterio antimimético : la novela de aventuras según Borges es superior porque no busca representar la realidad y se presenta como artificial. Pero también hay un criterio directamente compositivo : Borges destaca que en este tipo de textos no hay parte injustificada, es decir, que ninguna parte del texto ha sido dejada al azar durante su composición. En este prólogo ya vemos entonces trabajando implícitamente un modelo de composición y lo vemos además generando un doble efecto. Por un lado, determina un juicio crítico : el valor de una obra es mayor cuanto menor sea el azar que intervino en su composición, y por otro lado, promueve una determinada figura de autor : la de aquel que recurre a la inteligencia y la planificación para controlar el azar. También en este prólogo Borges defiende al género policial, como caso particular de un tipo de obras a las que describe

" de imaginación razonada »

como

(29). Este combate al azar que Borges promueve está entonces en la línea directa de Aristóteles y Poe, que lo habían declarado explícitamente.

El texto en el que Borges lleva al límite la idea del rechazo del azar como estrategia de composición había sido escrito nueve años antes, en 1931, y es el ensayo

«Una vindicación de la Cábala ». Podríamos decir que« Una vindicación de la cábala » es no sólo uno de sus ensayos seminales de poética sino la respuesta más concreta de

Borges a

«Filosofía de la composición » 
; y es además una declaración de aquello que en Borges deriva directamente de Valéry. En este ensayo, recordemos, Borges piensa en los escritores en términos de la cantidad decreciente de azar que aparece en sus textos o que interviene en su composición, y postula implícitamente al texto hipotético sin azar, compuesto por una igualmente hipotética mente infinita, como el ideal inalcanzable del texto literario. En la jerarquía de escritores que Borges presenta, el periodista ocupa el extremo inferior del espectro, el que incluye mayor cantidad de azar en los textos que produce, mientras que el extremo superior, el que está más cerca del ideal de la eliminación del azar, es ocupado por lo que Borges llama el escritor intelectual. Como ejemplos de este último tipo, Borges menciona dos escritores : uno es Thomas De Quincey, el otro es Paul Valéry 6 .

Valéry es una referencia recurrente en Borges, una figura simultáneamente de adhesión y de rechazo, con quien Borges mantiene una especie de contrapunto polémico a lo largo de su carrera literaria y que aparece de un modo crucial en uno de sus cuentos célebres :

«Pierre Menard, autor delQuijote »

. Borges no sólo reflexiona acerca de la composición en sus ensayos sino que también la transforma en material de su ficción.

«Pierre Menard...»

es un texto que puede verse como la escenificación de un método o procedimiento de composición y al mismo tiempo como la parodia o la reducción al absurdo de la composición. Es, por otra parte, el texto en el que Borges ajusta cuentas con Paul Valéry y su poética de exaltación del intelecto mediante la invención de un escritor conceptual inspirado en Valéry que es simultáneamente un doble de Borges y un fraude, ya que el cuento claramente da a entender que Menard en realidad copió esos dos capítulos del Quijoteque dice haber producido. Que« Pierre Menard, autor delQuijote »

participa de esos debates y quiere inscribirse hasta burlonamente en esas polémicas se hace evidente cuando Pierre Menard es presentado como un poeta simbolista

devoto esencialmente de Poe, que engendró a Baudelaire, que engendró a Mallarmé, que engendró a Valéry, que engendró a Edmond Teste $»(O C I$

: 447). El cuento puede incluso verse como un comentario irónico de algo que Valéry escribió en el ensayo «A propósito delCementerio marino " , uno de sus ensayos más conocidos, en el que se refirió a la composición como« la más poética de las ideas »(OeuvresI : 1504).

Las instancias en las que Borges se refiere al modelo de composición de Poe son muy numerosas para mencionarlas con exhaustividad, pero notemos que, como es típico en Borges, tienden a ser contradictorias. Algunas de las más relevantes por su importancia conceptual son el prólogo a

El informe de Brodiey su conferencia sobre el cuento policial (enBorges oral

). Y es especialmente significativo que en su libroIntroducción a la literatura norteamericana Borges dedica más atención y más párrafos a este ensayo de Poe que a cualquier otra obra de la tradición literaria norteamericana, incluyendo

Hojas de hierbade Whitman yMoby Dick

de Melville. Ya en 1935 Borges había escrito el ensayo« La génesis de "El cuervo" de Poe » , en el que analiza y evalúa favorablemente el procedimiento que Poe expone en« 
Filosofía de la composición ». En el final del artículo dice :«

El valor del análisis de Poe es considerable : afirmar la inteligencia lúcida y torpe y negar la insensata inspiración no es cosa baladí

»(Textos recobrados 1931-1956

123). Borges no desaprovecha la oportunidad para referirse irónicamente a Valéry, de quien dice que dedicarse a la inspirada refutación de la inspiración es su actividad vitalicia. Hacia el final de su vida, en 1982, casi cincuenta años después de aquel artículo, Borges fue invitado a dar una charla sobre la escritura de sus cuentos. Empezó esa charla diciendo :

Yo no creo, contrariamente a la teoría de Edgar Allan Poe, que el arte, la operación de escribir, sea una operación intelectual

(Borges en Lauro Zavala 1995 : 32). Pero en el resto de la charla ofrece un detallado relato de la composición de su cuento

«El Zahir »que sigue explícitamente el modelo de Poe.

Si bien Borges no escribió filosofías de la composición, sí imaginó escritores a los que les atribuyó textos análogos. Los principales entre esos escritores inventados son el ya mencionado Pierre Menard y Herbert Quain. El proyecto de Pierre Menard en relación al Quijote

se puede de hecho describir como el intento de imponer un relato de composición a un texto ya existente, cuyo sentido cambia como consecuencia de este nuevo relato de origen. Estos dos escritores, además de los que Borges inventó junto con Adolfo Bioy

Casares en las

Crónicas de Bustos Domecq

, deberían ser vistos como parte de esa suerte de contrapunto o diálogo subterráneo que Borges mantuvo con las vanguardias. Una de las curiosidades de la crítica sobre Borges es que hay probablemente tantos críticos que lo consideran un escritor de vanguardia como

los que lo consideran un enemigo de las vanguardias. ¿Cómo explicar este desacuerdo? Detengámonos un momento en este problema. El escritor argentino Juan José Saer alguna vez se refirió a Herbert Quain como

« un escritor de vanguardia muy interesante "

. La palabra vanguardia, también usada por algunos críticos para referirse a Quain, no aparece en el cuento, y el cuento tampoco dice que Quain (cuya figura, al igual que Pierre

Menard, es astutamente ambigua en su posible identificación con Borges) hubiera pertenecido a ningún grupo que pudiera ser considerado vanguardista 
- ¿A qué se debe entonces que la conexión resulte tan natural ? La explicación debe buscarse en esa suerte de diálogo secreto que Borges mantenía con los movimientos de vanguardia. Uno de los motivos por los que Borges puede ser considerado un escritor vanguardista es su interés en los métodos de composición y en las ideas relacionadas con ellos. Borges repetidamente negó los méritos de los artistas y escritores de vanguardia y de sus poéticas. Pero se opuso a ellos y los combatió en su propio terreno. Borges, digámoslo así, rechazó las concepciones vanguardistas de lo literario, pero escribió ese rechazo en el lenguaje de la vanguardia, y transformó preocupaciones y debates acerca de la composición en la materia misma de su ficción. Borges tal vez haya inventado algo que podríamos llamar, no sin paradoja, vanguardismo aristotélico 9.

La identificación de Borges con la línea de hacedores aristotélicos no es simplemente nominal ni se limita a la resistencia al azar. La relectura de la Poética

de Aristóteles permite ver las conexiones y continuidades entre ese texto y las ideas de

Borges. Los paralelos entre ambos son fáciles de notar y evidencian la pertenencia de Borges a esa tradición. Por ejemplo, Aristóteles había cuestionado las narraciones episódicas :

«

De las tramas y acciones simples, las episódicas son las peores ; y por episódica entiendo una trama en la que los episodios se suceden sin consideración de las leyes de probabilidad o necesidad. Es el tipo de tramas que construyen los poetas inferiores "(1415b, mi traducción). Borges razona de un modo análogo en el prólogo a La invención de Morel

, en el que al elogiar el rigor de la novela de aventuras, la opone a la falta de forma de la novela psicológica y a la mera sucesión de episodios en el Quijoteo en losViajes de Simbad

. Aristóteles hace la anterior observación en el marco de la discusión de uno de los conceptos centrales de su tratado : la causalidad. Borges reflexiona sobre ese mismo

concepto en

«El arte narrativo y la magia », otra vez como en eco con laPoética

. Aristóteles dice que los incidentes«

son más intensos cuando ocurren de modo inesperado, pero sin embargo a causa unos de otros. Ya que la maravilla está más presente en ellos si ocurren de esta manera que si ocurren espontáneamente y por azar

". Y también afirma que esos aspectos"

deben desarrollarse directamente a partir de la construcción de la trama »

(1452a). Tenemos en estas observaciones una proto-versión del«

orbe autónomo de corroboraciones y presagios "

al que Borges se refiere cuando describe elogiosamente elUlises

de Joyce hacia el final de su ensayo.

19 Otro de los ensayos de Borges de ese período, « La postulación de la realidad »

, escrito en 1931, puede también verse como la continuación de una reflexión aristotélica

(que a su vez continuaba una platónica) : la discusión acerca de la mímesis, los diversos modos en que la literatura puede relacionarse con la realidad.

« El arte narrativo y la magia "y« La postulación de la realidad » 
, por ende, deben ser vistos como la continuación de discusiones de poética clásica, concretamente sobre la causalidad narrativa y la mímesis, dos de las preocupaciones centrales en el tratado de Aristóteles y ejes de su continuo debate con Platón 10.

Veamos otro ejemplo en el que los ecos de las discusiones griegas entre platónicos y aristotélicos, o entre inspirados y razonadores, dan forma a la ficción de Borges. Me refiero al cuento « El Aleph »

- Recordemos que el núcleo de la trama de ese cuento es el conflicto entre dos escritores, que puede verse como una recreación del conflicto entre los modelos del ingenuamente mimético por un lado, representado por Carlos Argentino Daneri, y del conscientemente artificial por el otro, representado por ese personaje al que Borges llama Borges y que el cuento presenta como una suerte de neoaristotélico que reflexiona sobre las posibilidades del lenguaje y los límites de la representación. El cuento puede por lo tanto ser visto como una suerte de reducción al absurdo de lo mimético, y el poeta Daneri, que en el cuento compone su poema sobre el mundo transcribiendo las imágenes que ve en el Aleph, como instancia del poeta mimético ridiculizado por Platón.

Pero la conexión de este cuento con Platón no se limita a los alcances de una interpretación sino que hay una posible conexión más concreta. Leamos el siguiente pasaje del comienzo del libro X de la República

, justamente el libro en el que Platón discute el concepto de mímesis y en el que condena a los poetas :

Haciendo girar un espejo, muy pronto podrán hacerse el sol y los cielos, y la tierra y tú mismo, y otros animales y plantas, y todas las demás cosas de las que acabamos de hablar "(Platón,República

$\mathrm{X})$. Esas cosas de las que acababan de hablar son listadas unas líneas antes :

[...] embarcaciones de todo tipo, plantas y animales, el poeta mismo y todas las otras cosas : el cielo y la tierra, y las cosas que se encuentran en el cielo o debajo de la tierra ; y los dioses también

. Un espejo que gira y que refleja todas las cosas que hay en el cielo y la tierra, ¿no es una descripción precisa, casi una definición del Aleph ? Menos que una letra mística o una esferita cantoriana, el objeto mágico que Borges llama

«Aleph»

parece ser la transcripción física de un proceso de composición, un análogo fantástico de ese proceso. Tal vez sea entonces este cuento el texto en el que Borges interviene de manera más directa en el antiguo debate sobre creación literaria y sobre la figura del escritor como consecuencia de la relación que establece con la composición 11 . 
La poética de la ficción que se desprende de los textos programáticos de Borges y de los cuentos que escribió consiste en una versión personal del arte narrativo (que no necesariamente se restringe o se vincula al cuento) que incluye entre otros elementos la oposición al realismo, la negación de la novela psicológica o de caracteres (negación emparentada con la oposición al realismo), la valoración de la trama y del plan previo a la escritura, la vacilación y puesta en abismo entre ficción y realidad, la independencia temática respecto de determinismos geográficos o culturales, o la explotación estética y verbal de ideas y razonamientos

- También hay que decir que no siempre coinciden las preceptivas de sus textos programáticos con la práctica de los cuentos que escribe

. Pero los debates implícitos que esa poética mantiene con las vanguardias parecen jugarse en buena medida en la figura de autor, en el hacedor que protagoniza relatos de composición consciente y deliberada y que Borges transforma en materia de su ficción.

\section{Hasta acá vimos}

algunas instancias del relato de composición en Borges en relación con la escritura. Me gustaría ahora pasar a ver las relaciones que esos relatos establecen con su contracara, la

lectura. Concretamente, voy a analizar el rol que los modelos de lectura tienen como disparadores o matrices de escritura en la ficción de Borges. Es en el modo de pensar la lectura y de incluirla en su literatura donde Borges hace tal vez su mayor contribución al arte de la ficción.

\section{Modos de leer}

El Borges lector es sin duda uno de los mitos perdurables de la literatura del siglo XX. Que parecía haber leído una apreciable cantidad de libros, de literatura por cierto, pero también de filosofía, religión o historia, y que parecía recordarlos todos, es una parte central de la leyenda. Por la amplitud de lo que leyó, por la agudeza de sus ideas críticas, por la variedad de sus criterios de juicio, por la energía que desplegó en la tarea de comentar y analizar obras literarias o filosóficas, por la virtuosa habilidad para hacer conexiones y establecer mapas conceptuales, Borges lleva el rol del lector a un nivel sin precedentes. $Y$ además incluyó la lectura en su propia ficción, imaginándola y modelándola de maneras diversas y novedosas, ampliando y potenciando ese rol de lector que no sólo imaginó sino que en gran medida encarnó.

La marcada conciencia de Borges acerca de la lectura como actividad regida por determinadas reglas, supuestos y convenciones lo llevó a prestar especial atención a procedimientos y modelos de lectura. Una de las características más notables del Borges lector es justamente su capacidad para leer modos de leer. Tanto en« Pierre Menard, autor delQuijote »como en« Examen de la obra deHerbert Quain 》

, Borges incluye modelos de lectura específicos que actúan como generadores de escritura para esos escritores ficticios. En el caso de Pierre Menard tenemos " la atribución errónea y el anacronismo deliberado » como métodos o procedimientos de lectura que infunden vida a la reescritura delQuijote . En el caso de Herbert Quain, su libroStatementses presentado en términos de un modelo de lectura que incluye una forma de engaño, 
como deliberadamente escrito para frustrar expectativas de lectura y hacer que el lector crea haber inventado argumentos sólo sugeridos.

Y especialmentela novela policial de QuainThe God of the Labyrinth

, sobre la que volveremos, deriva de un tipo especial de lectura en la medida en que obedece a un plan según el cual es el lector quien puede potencialmente transformarse en el detective de la novela. $O$ sea que en el centro de la forma de esa novela imaginaria está

el lector.

Quisiera prestar atención a este proceso por el cual, por decirlo así, la exégesis es anterior

considerar la idea de que los modelos de lectura pueden funcionar como matrices de

escritura

. En muchos casos ocurre que los escritores se proponen escribir de modo que sus obras sean leídas de cierta manera específica. $O$ para decirlo de otra manera, en muchos casos

ocurre que un lector específico es uno de los personajes que esas obras se proponen

inventar. Esto hace que haya un vínculo directo entre modelos de lectura y relatos de composición, ya que el modelo de lectura pasa a ser un componente integral de la composición. El ejemplo canónico de este proceso por el cual un modelo de lectura llega a ser productor de escritura es la alegoría.

La alegoría surgió en la Grecia antigua como un modo de leer textos preexistentes que nada indica que hubieran sido escritos alegóricamente. Concretamente, fue desarrollada sobre todo por los estoicos con una doble finalidad: para justificar pasajes moralmente problemáticos de los poemas homéricos y para presentar a esos poemas como precursores de sus doctrinas filosóficas y de su concepción del mundo. Este modelo de lectura alegórico se desarrolló hasta tal punto, sobre todo promovido por la exégesis bíblica, que más tarde fue retomado por escritores y poetas que empezaron a escribir deliberadamente textos para que fueran leídos como alegorías ${ }^{14}$.

Esto es crucial para Borges. Así como sus escritores inventados Pierre Menard y Herbert Quain incluyen determinados modelos de lectura como engranajes de sus composiciones, podemos postular que también Borges lo hace en la suya. Lo que propongo a continuación es pensar la ficción de Borges a partir de modelos previos de lectura. La tesis anunciada al comienzo de este ensayo y que voy a tratar de justificar en lo que sigue es que buena parte de la ficción de Borges puede pensarse como resultado de fusionar o combinar dos modelos de lectura en particular que Borges identifica tempranamente : los que derivan del texto sagrado y del género policial.

\section{Los dos modelos : policial y texto sagrado}

Para empezar a analizar este aspecto de Borges, propongo detenernos en dos de las conferencias que pronunció hacia el final de su vida. Una de esas conferencias, de julio de 1977, tuvo por tema la cábala. Borges presta especial atención a los procedimientos de lectura cabalísticos, que presenta mediante una suerte de reducción al absurdo al imaginar a un cabalista leyendo el

Quijote. Este cabalista somete las palabras delQuijote 
a operaciones de permutación de las letras, de asignación de cantidades numéricas, de combinación con otras palabras aisladas y trata de deducir sentidos a partir de esas operaciones. Un pasaje muy parecido se encuentra en la conferencia sobre el cuento policial pronunciada un año más tarde, en junio de 1978. Nuevamente el Quijote

es sometido a una lectura que le es ajena : esta vez la de un lector del género policial que sospecha de los datos aportados por el texto y elabora conjeturas inútiles acerca de un texto que cree que lo engaña. En esta conferencia, Borges coloca al cuento policial inventado por Poe dentro del contexto más amplio de la concepción de la creación literaria de Poe, una concepción que Borges llama « intelectual" en la medida en que postula a la mente y no al espíritu como el agente de la composición. Podríamos decir que el policial es a la lectura lo que " Filosofía de la composición" es a la escritura. Borges destaca que Poe es no sólo el inventor de un género sino también de un tipo de lector, de una particular manera de leer.

Tanto el género policial como la cábala están muy presentes en la reflexión que Borges emprende en los primeros años treinta y que define su poética, su propio arquetipo de escritor. El ensayo « Leyes de la narración policial » de 1933 (reescrito dos años más tarde como « Los laberintos policiales y Chesterton »), así como numerosas reseñas de novelas policiales que publica en las revistas SuroEl Hogar

, o la labor de antólogo a la que se dedica, son signos de la importancia que el policial tiene para Borges en esos años. A Borges le atraen múltiples aspectos del policial. Algunos de ellos son la necesidad de inventar con rigor, la artificialidad de su forma, la exigencia de planificar y diseñar la trama, una particular relación con la verdad, y sobre todo el nuevo lector, el nuevo modo de leer que impone el género : la lectura de la sospecha, la lectura paranoica de quien busca evitar ser engañado.

Borges, se ha repetido muchas veces, trabaja con los límites de la ficción, con los contornos que separan ficción y realidad. Se podría igualmente decir que trabaja con la línea, que él tensa de múltiples formas, entre ficción y mentira. Uno de los criterios que separan a ambas es la intención del enunciador : la mentira implica una intención de engañar, mientras que la ficción se presenta a sí misma como tal ; mientras una es culpable, la otra es inocente. El título

Ficciones

fue entendido de distintas maneras. Hay traductores al inglés y críticos de lengua inglesa que han preferido dejar la palabra en español, en lugar de la transparente

fictions

, como manera de sugerir que lo que Borges llama « ficciones » es en realidad otra cosa, diferente de lo que hasta ese momento se había llamado así y con características propias. Otra manera de entenderlo es como declaración de la artificialidad de la literatura, en la

línea de los « artificios » que alejan la ficción del realismo. La lectura que me interesa proponer es compatible con las anteriores, y es la que ve en la elección de esa palabra una indicación o advertencia sobre la reducción de su inocencia y la ampliación de su dimensión engañosa y culpable 15 . 
Este tensionar la ficción en la dirección del engaño, este recurrir a la ficción que no se presenta a sí misma como tal sino que esconde su condición de ficción, se puede ver en Borges funcionando de dos maneras o en dos niveles. Por un lado, está el funcionamiento de la ficción como engaño dentro de sus cuentos, entre personajes. Hay múltiples ejemplos de este tipo, de lo que podríamos llamar ficciones del engaño. Uno

« Emma Zunz », el cuento en el que la heroína inventa una historia ficticia para cometer un asesinato sin ser considerada culpable. Otro es « El tema del traidor y del héroe », en el que un grupo de conspiradores nacionalistas irlandeses inventa una versión ficticia de

ciertos hechos históricos para proteger la memoria del héroe nacional. Otro es « El muerto ", en el que un joven cree que está a punto de cumplir su ambición de reemplazar al jefe de una banda criminal sólo para descubrir, justo antes de ser asesinado, que todo había sido una puesta en escena para engañarlo. Por cierto, « Tlön, Uqbar, Orbis Tertius » es la historia de un grupo de conspiradores que se propone la redacción de un mundo ficticio para que sea aceptado como realidad. Y tal vez el mejor ejemplo sea « La muerte y la brújula ", en el que el criminal inventa una compleja ficción con el objetivo de atrapar y matar al detective, que cegado por lo que cree que es su astuto desciframiento de la trama criminal es incapaz de ver la realidad de sentido común que tiene frente a sus ojos. Podríamos proponer la siguiente generalización : el que pone a circular una historia en Borges es el que miente, el que engaña.

Por otro lado, tenemos el engaño en el nivel de la presentación de sus textos, en los que la clasificación genérica es en algunos casos deliberadamente manipulada para generar una ambigüedad que se parece a la mentira. En esta línea está « Pierre Menard, autor del Quijote

", texto ficticio pero maliciosamente presentado con los protocolos de textos que no son ficción. Es decir, se trata de un texto cuyo contenido no tiene elementos del policial, pero que tiene que ser leído con las estrategias de lectura del policial, sospechando. « Pierre Menard... » de hecho participa de los dos niveles, ya que por cierto puede ser leído (y tal vez deba ser leído) como la historia de un impostor contada por un admirador crédulo y engañado. También «El acercamiento a Almotásim », una ficción publicada dos años antes, tenía el mismo aspecto de ensayo, presentado como si fuera la reseña de una novela

policial hindú, con referencias a publicaciones, lugares y autores reales, y además publicado en un libro de ensayos. Esto es desde luego muy conocido y no es necesario repetirlo. Más interesante es verificar que Borges advierte al lector acerca de todo esto, aunque de un modo algo indirecto que puede pasar desapercibido, y lo hace en su propia ficción. Recordemos el párrafo que aparece al comienzo de "Tlön, Uqbar, Orbis Tertius » en la voz del narrador :

Nos demoró una vasta polémica sobre la ejecución de una novela en primera persona, cuyo narrador omitiera o desfigurara los hechos e incurriera en diversas contradicciones, que permitieran a unos pocos lectores-a muy pocos lectores-la adivinación de una realidad atroz o banal. (

OCI 431) 
Es en este párrafo de la primera página del primer cuento deFicciones

donde podemos decir que el lector de Borges nace explícitamente : un párrafo acerca de una narración en primera persona incluido en una narración en primera persona. Y ese

lector nace con una advertencia : lo que se le cuenta no es confiable y puede estar escondiendo otra realidad detrás de la realidad evidente. No cuesta reconocer los rasgos generales de este lector. Para decirlo nuevamente, es el lector inventado por el género policial. Borges saca a este lector (cuya fe es la paranoia, y cuya tarea es sospechar, desconfiar y evitar ser engañado) del contexto del género policial y lo coloca en el centro de su literatura. También en otros cuentos encontramos advertencias de que es necesario mantener activa esta lectura desconfiada. En

« La lotería en Babilonia »

el narrador (siempre en estos casos se trata de narraciones en primera persona) nos dice : «

Yo mismo, en esta apresurada declaración, he falseado algún esplendor, alguna atrocidad »(OCI 460). Y en« El congreso »leemos :«

No falsearé deliberadamente los hechos, pero presiento que la haraganería y la torpeza me obligarán, más de una vez, al error $»(O C$

III 20). Borges hace de este lector, que necesita sospechar y mantenerse alerta, una suerte de personaje detectivesco y heroico que será una silenciosa presencia que atraviesa su literatura, una suerte de protagonista secreto de su ficción.

Así como el policial aparece en la reflexión de Borges de los tempranos años treinta, también la cábala ya está presente, como lo testimonia el ensayo « Una vindicación de la cábala ", de 1931. Este ensayo, repitamos, propone al texto sagrado, del modo en que es leído por ciertas tradiciones exegéticas, como el modelo y la aspiración del texto literario : un texto cuyo significado potencial se expande indefinidamente, que puede ser sometido a interpretaciones sin fin y que genera lecturas no exentas, incluso, de alucinación y delirio. Como ya dijimos, este texto de Borges debería ser descripto como una teoría de la lectura en relación a supuestos de composición. Borges recurre a la cábala porque en esa doctrina el proceso de lectura es llevado al límite. Tomando esa doctrina como parámetro, Borges implícitamente promueve un esfuerzo paralelo por parte del autor literario. Para Borges, el texto ideal está, por decirlo así, en el límite del esfuerzo intelectual del escritor, que guía la construcción de su obra de modo de reducir cuanto sea posible la participación del azar en el proceso de composición. Y el autor ideal es aquel que fuerza su mente en dirección al intelecto absoluto, y que aspira a producir textos que incluyan la promesa de múltiples sentidos posibles y que pidan ser leídos de ese modo particular. La identificación entre el texto literario y el sagrado es recurrente en

otra de sus conferencias del año 1977, esta vez sobre la poesía, Borges comienza recordando dos citas sobre las Escrituras : una de Escoto Erígena, el teólogo medieval irlandés, y la otra de un cabalista medieval anónimo. La primera se refiere a los infinitos sentidos del texto bíblico, la otra a la idea de que hay tantas Biblias como lectores de la Biblia. Y agrega :

Me atrevo a decir que son exactas, no sólo en lo referente a la Escritura sino a cualquier libro digno de ser releído

$»(O C$ 
III 278). Para Borges el texto sagrado ha sido constantemente un modelo y un ideal para el texto literario, y lo pensó sobre todo en términos de mecanismos y procedimientos de lectura directamente relacionados a un relato de composición 16.

La cuestión de los dos modelos de lectura puede traducirse y simplificarse a términos más concretos. Todos hemos tenido, como lectores de Borges, una doble experiencia. Por un

lado, la experiencia de haber aceptado algo que finalmente se revela como falso o engañoso, o al menos la experiencia de tener que medir nuestra dosis de credulidad, cierta prevención para evitar tomar como existente algo que es en realidad ficticio, o viceversa. La experiencia poética que propone Borges muchas veces es la opuesta de la que promovía Coleridge : la voluntaria suspensión no de la incredulidad sino de su contrario. Esta modalidad de lectura escéptica y desconfiada es la que Borges identifica con el género policial. Por otro lado, también hemos tenido la experiencia de haber percibido tardíamente sentidos o posibilidades de los textos que, si bien ya estaban ahí,

no habíamos notado en una primera lectura. Esa multiplicación de sentidos y de posibilidades de significación que se revelan en la relectura Borges la identifica con el texto sagrado. A partir de esta doble experiencia en tanto lectores, podemos postular que Borges es también el inventor de un nuevo tipo de lector. Un lector que, para simplificarlo en un esquema, surge de combinar los procedimientos de la exégesis religiosa, que confieren potencialmente sentido plural a cada parte del texto, con la desconfianza y suspicacia del lector del género policial, que trata de anticiparse a las trampas que el escritor de policiales le tiende.

\section{Almotásim y Abenjacán}

Podemos considerar la fusión de estos dos modelos de lectura como una de las marcas centrales de la ficción de Borges, su gran experimento en el ámbito de la ficción. Un experimento que concibió temprano en su carrera de narrador y que deliberadamente se propuso llevar a cabo. Como Borges mismo diría, el experimento salió tan bien que nadie

se dio cuenta de que se trataba de un experimento. En realidad, apenas necesitamos especular acerca de este proyecto : él lo declara casi explícitamente al comienzo mismo de su ficción. Sus instrucciones de lectura se encuentran incluidas en aquel temprano cuento camuflado en un libro de ensayos de 1936 : «El acercamiento a Almotásim ». Recordemos que este texto adopta la forma de una reseña sobre una supuesta novela hindú del mismo nombre. En el párrafo inicial, Borges incluye comentarios críticos que atribuye a otros dos comentaristas y que describen la novela, en un caso, como una "combinación algo

legóricos del Islam y de novelas policiales clásicas, y en el otro caso, como una obra escrita

«bajo la doble, inverosímil tutela »

de Wilkie Collins, autor de novelas policiales, y del poeta persa Attar, autor de poemas religiosos. Borges resume así estos comentarios :

Esencialmente, ambos escritores concuerdan : los dos indican el mecanismo policial de la obra, y su undercurrentmístico »(OCI 414). 
, como Borges la llama, debe verse como el anuncio temprano de una de las sólidas

fundaciones de la ficción de Borges, en la que buscó combinar de diversas maneras esos

dos elementos :

« el mecanismo policial »y el « undercurrentmístico »

. Dicho de otra manera, podemos postular que

una parte significativa de la ficción de Borges puede pensarse como producto de la matriz de los modelos de lectura que Borges detecta en el texto sagrado y en el género policial, y que le permiten innovar y llevar al cuento procedimientos que renuevan la práctica del

17.

género

Bastante se ha escrito sobre Borges y el género policial, que está presente de múltiples

. Igualmente múltiples son las presencias y figuraciones del texto sagrado. El objeto al que Borges llama Aleph puede verse sin mayor dificultad, en tanto elemento que incluye y refleja la totalidad, como una alusión o cifra del texto sagrado, como también lo indica la referencia cabalística de su nombre. « La biblioteca de Babel », cuyo título alude a la Biblia, $\mathrm{y}$ « El libro de arena », que comienza con la llegada de un vendedor de biblias, son otras instancias de esto mismo. Y recordemos que Borges nombra al Zahir a partir del nombre de una de las escuelas de exégesis del Corán; es decir que el texto sagrado como modelo de lectura está también presente en la concepción misma de este cuento.

En la novelaThe God of the Labyrinth

que Borges le atribuye a Herbert Quain aparece la conjunción de ambos modelos : por un lado, se trata de una novela policial ; por otro lado, el título es casi una definición de texto sagrado. Tanto la Biblia como el Corán han sido descriptos por teólogos y exégetas como laberintos de palabras y de sentidos entre los que se adivina la presencia de Dios. Este proyecto de novela imaginaria es aún más significativo en la medida en que podemos postular que su plan corresponde a un cuento posterior de Borges : « Abenjacán el Bojarí, muerto en su laberinto ». Recordemos que el plan de la novela de Quain consiste en presentar un asesinato enigmático seguido de una discusión progresiva, proponer una solución al final y agregar un párrafo retrospectivo que deja entender que la solución es errónea. Completa Borges : « El lector, inquieto, revisa los capítulos pertinentes y descubre otrasolución, que es la verdadera. El lector de ese libro singular es más perspicaz que el detective ». (OC I462 ; énfasis original) 
Sin entrar en el análisis detallado de « Abenjacán... », recordemos que se trata de una trama policial clásica, que empieza con el relato de un asesinato enigmático ocurrido varios años antes y que es discutido en el cuento por los dos amigos protagonistas, uno matemático y otro poeta. El poeta cree en una solución fantástica que involucra la participación de un fantasma, pero el matemático, que escucha esta explicación con el correspondiente escepticismo, al final del cuento propone una solución realista. Este cuento ha sido mirado con cierta perplejidad por la crítica, ya que parece indicar que Borges cierra su intervención como autor en el género policial volviendo a un relato de trama clásica después de las innovaciones formales que había presentado en cuentos como « La muerte y la brújula » $\mathrm{y}$ « El jardín de senderos que se bifurcan ». Pero una serie de indicios nos permiten postular que estamos ante un cuento por lo menos tan original e innovador como esos otros. Se trata de un relato que parece haber sido escrito siguiendo

el modelo de la novela policial de Quain, de modo que el lector puede proponer una solución alternativa a la solución poco convincente propuesta por el matemático. Si se observa la circulación de la información en el cuento se verifica que la trama está cuidadosamente armada de modo que todos los datos que los personajes manejan para saber lo que pasó y proponer la posible solución del misterio provienen de una única fuente. Esa fuente es otro de los personajes : el rector Allaby, que no sólo es el único testigo e informante del asesinato de Abenjacán sino que además había manifestado encono hacia la víctima. Observemos también que inmediatamente después del cuento Borges incluye el breve texto « Los dos reyes y los dos laberintos ", que una nota al pie aclara que es el sermón condenatorio que Allaby había pronunciado. 0 sea que este texto breve puede verse funcionando como el párrafo retrospectivo del plan de Quain. Esto que propongo es menos una interpretación del cuento que una descripción del modo en que está construido, es decir, una lectura de su composición. Y esa composición hace que « Abenjacán... » pueda ser leído de modo de ver gran parte de la historia que enmarca al asesinato como la invención fantasiosa del rector Allaby, y por lo tanto ver a Allaby como sospechoso del crimen. Borges le da al lector la posibilidad de ser Treviranus, el policía de

« La muerte y la brújula » cuyas conjeturas de sentido común son sistemáticamente descartadas por el detective pero que resultan ser correctas. Es decir, Borges le da la posibilidad al lector de postular que si hay un único testigo de los crímenes, que además exhibió desprecio por la víctima, ese es el principal sospechoso. Notemos que esta lectura devuelve al cuento al cauce de la trama más borgeana : el que cuenta una historia, el que pone a circular un relato es el que engaña. El rector/lector Allaby, solitario lector en su

biblioteca de libros ingleses, aparece entonces como el autor tramposo de una trama ficticia de dobles y personalidades intercambiadas, de estructura y ámbito milyunanochescos, y por lo tanto como el tal vez más borgeano de esos personajes que Borges pone a circular en su literatura como posibles dobles de sí

19. 
También señalemos que los dos amigos que protagonizan ese cuento, un matemático y un poeta, son también figuras de lector y encarnaciones de dos modos de leer opuestos, manifestados en el exceso de credulidad del poeta y en el exceso de suspicacia del matemático. Todo esto hace que «Abenjacán » pueda verse como el cuento en el que el lector de Borges, surgido en gran medida de la fusión de esos dos modelos de lectura, llega a su culminación. Podríamos decir que el desarrollo de este lector dibuja entonces un arco que se inicia con los primeros párrafos de « El acercamiento a Almotásim », en los que nace, encuentra su confirmación explícita en el comienzo de « Tlön, Uqbar, Orbis Tertius » y se cierra más de quince años después con « Abenjacán el Bojarí, muerto en su laberinto ", uno de los últimos cuentos que Borges agrega a

El Aleph

en 1952 y cuyo plan había sido anticipado años antes en « Examen de la obra de Herbert Quain ». Teniendo en cuenta el rol único y privilegiado que el lector parece tener reservado en "Abenjacán... », tal vez no resulte excesivo proponerlo como el cuento paradigmático de esa poética y por lo tanto como un cuento central en la narrativa de Borges.

\section{Derivaciones filosóficas}

Hay algo más que me gustaría agregar. Que esta fusión de los dos modelos de lectura va para Borges más allá de la lectura y la composición de literatura. Que esos dos elementos que Borges intenta yuxtaponer, el texto sagrado y el policial, pueden a su vez verse como

figuras de dos tradiciones intelectuales histórica y conceptualmente divergentes : la exégesis religiosa por un lado y el pensamiento analítico por el otro, la hermenéutica y la lógica, una basada en la interpretación y la analogía y la otra en el razonamiento y la deducción. Dos líneas que, a su vez, se corresponden con las dos tradiciones reconocibles a lo largo del siglo XX y todavía presentes en la actualidad como escuelas filosóficas contrapuestas : la filosofía continental y la filosofía analítica, una asociada con ciertas corrientes alemanas y francesas, y la otra asociada con el pensamiento anglosajón. Esto tal vez nos permita explicar un hecho bastante notable, al que la crítica no le ha prestado mayor atención. Es el hecho de que Borges es reconocido como referente por pensadores de tendencias intelectuales opuestas que ni siquiera se leerían entre sí. Si pensamos en la tradición continental o hermenéutica, más próxima a los estudios literarios y de la que proviene gran parte de la teoría literaria, vemos que Borges y sus ideas están presentes en obras, por ejemplo, de Michel Foucault, Jacques Derrida, Gilles Deleuze, Jean-François Lyotard o Maurice Blanchot. Estos nombres han sido repetidamente mencionados por la crítica al referirse a la influencia y al legado de

Borges. Mucho menos mencionados o directamente ignorados son nombres que pertenecen a una tradición muy diferente, de pensadores próximos a la tradición analítica, como Daniel Dennett, Douglas Hofstadter, Steven Pinker, Martin Gardner o Raymond Smullyan, vinculados a la filosofía de la mente, a las ciencias cognitivas y del lenguaje, a la matemática o a la lógica, y que también han manifestado afinidad y admiración por las ideas de Borges. No es un logro menor. De hecho, no sé de otra figura del panorama intelectual del siglo XX de la que pueda decirse lo mismo. 
Una explicación que podemos aventurar es que Borges no sólo percibió dos modelos de lectura diversos provenientes de esas dos tradiciones enfrentadas y que él buscaría combinar en su ficción, sino que también hizo el esfuerzo intelectual de explorar y entender las posibilidades y los límites de ambas tradiciones de pensamiento, y que como resultado de ese esfuerzo deliberado logró formular ideas que fueran inteligibles y significativas para las dos escuelas disidentes. Pero lo realmente notable es que Borges logra presentar ideas o conceptos que resultan atractivos para pensadores de ambas líneas y al mismo tiempo mantenerse al margen de esas escuelas. Sería igualmente desatinado identificar a Borges como intelectual hermenéutico o como intelectual analítico, aunque tiene elementos de ambos. Su presencia es incongruente en cualquiera

omo si hubiera creado un ámbito propio del pensamiento, gobernado por reglas y conexiones que hasta el momento no habían sido ensayadas.

La discusión que comenzó en los albores de la filosofía con la oposición de platónicos y aristotélicos relacionada con dos relatos de composición contradictorios, termina con la oposición entre dos corrientes filosóficas contemporáneas relacionada con dos modelos de lectura de funcionamiento divergente. Tal vez no se trate de un simple truco de composición que el arco trazado por la exposición de la poética de la ficción de Borges se corresponda y se haga eco con el arco trazado por la historia de la filosofía.

\section{BIBLIOGRAFÍA}

Aristóteles.Poetics

. Trad. Stephen Halliwell. Loeb Classical Library XXIII. Cambridge, Mass. : Harvard University Press, 1995.

Bioy Casares, Adolfo.Borges. Buenos Aires : Destino, 2006.

Borges, Jorge Luis.Obras completas. 4 vols. Barcelona : Emecé, 1989-96.

Borges, Jorge Luis.Obras completas en colaboración.Buenos Aires : Emecé, 1991.

Borges, Jorge Luis.Textos recobrados 1919-1929. Barcelona : Emecé, 1997.

Borges, Jorge Luis.Textos recobrados 1931-1955. Barcelona : Emecé, 2001.

Borges, Jorge Luis. « Así escribo mis cuentos ».La escritura del cuento (Teorías del cuento II)

. Ed. Lauro Zavala. México : UNAM, 1995.

Fernández Vega, José. « Una campaña estética. Borges y la narrativa policial ».Variaciones Borges 1 . (1996) : 27-66.

Lamberton, Robert.

Homer The Theologian. Neoplatonist Allegorical Reading and the Growth of the Epic Tradition.

Berkeley, Calif. : University of California Press, 1989. 
Parodi, Cristina. « Borges y la subversión del género policial ».

Borges : desesperaciones aparentes y consuelos secretos

.Ed. Rafael Olea Franco. México : El Colegio de México, 1999, 77-97.

Pastormerlo, Sergio.Borges crítico. Buenos Aires : Fondo de Cultura Económica, 2007.

Piglia, Ricardo. « Ideología y ficción en Borges ».Punto de vista5, 1980 : 3-6.

Platón.The Republic.Trad. Benjamin Jowett.12 agosto 2014. <

http://classics.mit.edu/Plato/republic.html>

Poe, Edgar Allan. « The Philosophy of Composition ».12 agosto 2014. <

http://www.eapoe.org/works/essays/philcomp.htm>

Premat, Julio.Héroes sin atributos. Figuras de autor en la literatura argentina

. Buenos Aires : Fondo de Cultura Económica, 2009.

Ruiz, Pablo Martín. «El último cuento policial de Borges y lo que había en el laberinto ».

Variaciones Borges14 (2002) : 203-35.

Ruiz, Pablo Martín.

Four Cold Chapters on the Possibility of Literature Leading Mostly to Borges and Oulipo.

Dublin/ London : Dalkey Archive Press, 2014.

Stratta, Isabel. « Documentos para una poética del relato ». En Sylvia Saítta (ed.).

Historia crítica de la literatura argentina. Vol 9 :El oficio se afirma. Buenos Aires : Emecé, 2004. 39-63.

Valéry, Paul.Euvres. Ed. Jean Hytier. Bibliothèque de la Pléiade. 2 vols. Paris

: Gallimard, 1957-1960.

\section{NOTAS}

1.

Para un análisis más detallado del relato de composición como género, de su genealogía y de algunas de sus manifestaciones e implicaciones conceptuales, ver mi libro Four Cold Chapters on the Possibility of Literature Leading Mostly to Borges and Oulipo

. Buena parte de las ideas sobre Borges que presento en este artículo pueden también encontrarse

en el libro.

2. Las traducciones son mías.

3.

Habría que observar también que el Homero que Borges imagina en el breve texto «El hacedor » no encuentra la fundación de su oficio en el ejercicio del intelecto y la razón, o en el aprendizaje y la adquisición de habilidades, sino más bien en la memoria que trabaja un pasado de aventura y de violencia. Como casi siempre, Borges enrarece y complica las oposiciones con las que trabaja.

4.

El concepto de figura de autor es desde luego complejo y puede incluir múltiples aspectos, relacionados por ejemplo con la relación del autor con el canon nacional, con su lugar en la tradición, etc. Para un tratamiento de otros aspectos de la figura de autor en Borges, ver el capítulo pertinente en el estudio de Julio Premat

Héroes sin atributos.

5.

El ya canónico ensayo de Ricardo Piglia « Ideología y ficción en Borges » presenta y analiza el sistema de oposiciones, a partir de los dos linajes de la trama familiar, como mito de origen y eje que estructura la literatura de Borges. 
6.

En el ensayo sobre la cábala la composición es también central en otro sentido. Recordemos que lo que Borges se propone entender en este ensayo es el aparente sinsentido de los procedimientos de lectura cabalísticos. Borges explica esos procedimientos mediante una hipótesis de composición. Borges observa que los excesos exegéticos de los cabalistas derivan del modo en que ellos suponían que los textos bíblicos habían sido escritos. La pasión interpretativa de los cabalistas es, sostiene Borges, la conclusión lógica que se sigue del principio que los cabalistas adoptaron : que las Escrituras fueron compuestas por una mente absoluta, infinita, y por lo tanto la injerencia del azar en su composición es nula. Una vez admitido ese principio, que

es un relato de composición, no hay manipulación textual que resulte excesiva. Este ensayo, entonces, a pesar de su título engañosamente esotérico, es antes que nada una reflexión acerca de la lectura en función de supuestos de composición, acerca de cómo la lectura es afectada por la manera en que imaginamos que los textos fueron compuestos. Dicho de otra manera, acerca del relato de composición como componente del sentido de los textos.

7.

En conversación con estudiantes de doctorado en la universidad de Princeton, en 2003. Transcripción no publicada.

8.

Herbert Quain, un vanguardista escéptico de las vanguardias, es en muchos sentidos (al modo de M. Teste en relación con Valéry) una versión enfática de Borges. Crear esta versión extrema de sí mismo puede verse, entre otras cosas, como una estrategia que le permite a Borges forjar para su

literatura una posición más sólida, un nuevo centro desde el cual anticipar y absorber juicios futuros.

9.

No habría que desatender la entidad doble y femenina que Borges anuncia al comienzo de « Herbert Quain », cuando dice que un libro de Quain había sido comparado por la crítica con Agatha Christie y otros con Gertrude Stein. Policial y vanguardia ; literatura popular y literatura experimental. No es un mal retrato de Borges.

10.

Siempre adepto a las vías indirectas, la declaración más explícita del aristotelismo de Borges tal vez se encuentre en el cuento « La busca de Averroes », en el que Borges no sólo se identifica con

el aristotelista Averroes en el fracaso paralelo de ambos (Averroes fracasa en el intento de traducir las palabras « tragedia » $\mathrm{y}$ " comedia », Borges fracasa en el intento de representar a Averroes en su cuento), sino que en la discusión sobre poética que los personajes tienen en el cuento, concretamente sobre la tensión entre originalidad y tradición, Borges pone en boca de Averroes argumentos que hace propios en otros textos suyos, especialmente en el poema « Arte poética ».

11.

No habría que dejar de notar, por otra parte, que este cuento también parece indicar, en la línea

Divina comedia

de Dante y la

, y en delicado contrapunto con el hacedor aristotélico, una suerte de anhelo de la visión total, con connotaciones místicas e incluso amorosas, como condición ideal para la composición literaria.

12.

Para una inteligente exposición de los principales elementos de la poética de la narración en Borges, ver Stratta 2004. 
13.

Por ejemplo, Borges defiende y exalta el cuento policial clásico pero no escribe ninguno, y rechaza la violencia y el sexo del policial negro pero escribe « Emma Zunz » y « El muerto », que incluyen dosis de ambos elementos en engranajes narrativos que no es difícil emparentar con el policial negro. Incluso « Hombre de la esquina rosada », el origen mismo del Borges cuentista, puede verse en esa línea del policial de la que Borges toma distancia.

14. Este largo proceso está detalladamente analizado en Lamberton 1989.

15.

Suele pensarse la ficción como opuesta a la verdad de la realidad, como si realidad y verdad estuvieran necesariamente vinculadas y se bastaran recíprocamente. Pero la realidad le es igualmente necesaria a la mentira : si la mentira no es tomada por realidad no puede funcionar como tal. Curiosamente, podríamos ver en este rasgo un acercamiento al realismo por parte de Borges. Al trabajar dentro de su ficción con relatos que tratan de imponerse como verdaderos,

como un posible funcionamiento de la realidad, Borges introduce en sus textos un elemento realista, una especie de realismo en espejo. Dicho de otra manera, hay un realismo en Borges que se manifiesta a través de la mentira.

16.

Es un hábito en Borges la aproximación y hasta la identificación de los ámbitos literario y religioso. En su vocabulario crítico abundan palabras como superstición, culto, secta, sagrado, místico, etc. Para un análisis de este aspecto, ver Pastormerlo 2007. Cabría agregar, incluso, que una de las acepciones posibles de la palabra « hacedor » es como referencia a Dios.

17.

En esto también hay una posible conexión con Valéry. Borges señala esta misma combinación de policial y teología en « Valéry como símbolo », el ensayo que escribe cuando muere Valéry, en 1945 : « Para nosotros, Valéry es Edmond Teste. Es decir, Valéry es una derivación del Chevalier Dupin de Edgar Allan Poe y del inconcebible Dios de los teólogos ». (

OCI : 64)

18. Ver, por ejemplo, los ensayos de José Fernández Vega (1996) y de Cristina Parodi (1997).

19.

Esto es algo sobre lo que ya escribí anteriormente. Para un análisis más detallado, incluyendo posibles sentidos vinculados al contexto histórico de las dos guerras mundiales, ver Ruiz 2002. 


\section{RESÚMENES}

La relativamente tardía aparición de lo que consideramos el centro de la ficción de Borges a partir de los años cuarenta puede verse como el resultado de la progresiva elaboración de una poética de la ficción. Algunos de los aspectos centrales de esa poética están relacionados con modelos de lectura y, en una línea que se vincula con las vanguardias, con modelos de composición. El objetivo de este artículo es analizar el modo en que Borges se posicionó con respecto a los debates sobre composición por un lado y el modo en que usó modelos de lectura como matriz de su ficción por el otro. Concretamente, me propongo mostrar que Borges usa y

combina los modelos de lectura del texto sagrado y del género policial como matrices de escritura, al punto que esta combinación puede verse como fundacional de una parte significativa de su ficción ; y que a su vez esos modelos de lectura están directamente asociados con modelos de composición y de figuras de autor, de los que en cierto modo provienen y que estructuran los textos programáticos de Borges de los años treinta y cuarenta.

L'apparition relativement tardive de ce que nous considérons comme le noyau de la fiction borgésienne à partir des années 1940 peut être considéré comme le résultat de l'élaboration progressive d'une poétique de la fiction. Quelques uns des aspects centraux de cette poétique sont attachés à des modèles de lecture et, dans une lignée à mettre en relation avec les avantgardes, à des modèles de composition. L'objet de cet article est d'analyser d'une part le positionnement de Borges face aux débats sur la composition et, d'autre part, la façon dont il s'est servi des modèles de lecture comme matrices de sa fiction. Concrètement, je me propose de montrer que Borges utilise et combine des modèles de lecture du texte sacré et du genre policier en tant que matrices d'écriture, au point même que cette combinaison peut être perçue comme constitutive d'une partie significative de sa fiction. À leur tour, ces modèles de lecture sont en étroite relation avec des modèles de composition et des figures d'auteur, d'où ils proviennent en quelque sorte, et qui structurent les textes programmatiques de Borges dans les années trente et quarante.

What we consider to be the kernel of Borges's fiction starts to be published in the forties, somewhat late in Borges's literary career. This timing can be seen as the result of the careful elaboration of a poetics of fiction. Some of the central aspects of that poetics are related to reading models and, in a line that connects directly with the avant-garde, to models of composition. The goal of this article is to analyze the way in which Borges positioned himself in the debates about composition on the one hand, and the way in which he used reading models as matrices for his fiction on the other. More precisely, I suggest that Borges uses and combines the two reading models of the sacred text and detective fiction as matrices of writing, to the extent that this combination can be seen as foundational for a significant part of his fiction ; and that

those reading models, in turn, are directly related to models of composition and authorial figures, from which they originate and which provide the backbone of the programatic texts that Borges produces in the thirties and forties. 
ÍNDICE

Mots-clés: Borges, poétique, récit de composition, modèles de lecture, genre policier, texte sacré Keywords: poetics, account of composition, reading models, detective fiction, sacred text.

Palabras claves: poética, relato de composición, modelos de lectura, policial, texto sagrado.

\section{AUTOR}

PABLO MARTÍN RUIZ

Tufts University

pablo.ruiz@tufts.edu 